$\underline{\text { Review Article }}$

\title{
THE RECENT UPDATE OF DEOXYARBUTIN: A SKIN DEPIGMENTATION AGENT WITH TYROSINASE INHIBITION TARGETING
}

\author{
MUCHTARIDI MUCHTARIDI ${ }^{*}$, MENTARI LUTHFIKA DEWI ${ }^{1}$
}

\author{
1Department of Pharmaceutical Analysis and Medicinal Chemistry, Faculty of Pharmacy, Jl, Universitas Padjadjaran, Jl KM 21.5 Bandung \\ Sumedang, Jatinangor, 45363, West Java
}

Email: muchtaridi@unpad.ac.id

Received: 28 Jan 2020, Revised and Accepted: 29 Feb 2020

\begin{abstract}
Melanin is produced through the process of melanogenesis, which serves to protect the skin from the damaging effects of UV radiation. Abnormal accumulation of melanin will aesthetically disturb even interfere with health. One of the clinical manifestations of abnormal accumulation of melanin is the incidence of melasma. Some of the tyrosinase enzyme inhibitor agents most widely used as Hydroquinone, Kojic acid and Arbutin do not give satisfactory results and cause serious side effects. Hydroquinone is known to cause ochronosis exogenous and cytotoxic. Kojic acid is known to cause allergies and mutagenic, while arbutinisis is known to have cytotoxic properties lower than hydroquinone, but less satisfactory depigmentation activity. There was a compound that has been synthesized by removing the hydroxy group of arbutin, known as deoxyarbutin (4[Tetrahydro-2H-Pyrans-2-yl) oxy] phenol). Deoxyarbutin (dA) shows Ki 10-fold is lower than hydroquinone and 350-fold is lower than arbutin. $\mathrm{IC}_{50} \mathrm{dA}$ is $17.5+0.5 \mu \mathrm{mol} / \mathrm{l}$, while the $\mathrm{IC}_{50}$ hydroquinone is $73.7+9.1 \mu \mathrm{mol} / \mathrm{l}$. In terms of security, $\mathrm{dA}$ indicates that cell viability is $95 \%$ higher than hydroquinone. However, $\mathrm{dA}$ is thermolabile and photolabile. Several studies have shown satisfactory results to improve the stability of $\mathrm{dA}$, that these compounds are considerable potential for further development as a depigmentation agent. The aim of this review is to describe how the potency of $\mathrm{dA}$ as a tyrosinase inhibitor interferes melanogenesis process through the latest depigmentation agent, its safety, efficacy and stability.
\end{abstract}

Keywords: Melanin, Deoxyarbutin, Tyrosinase inhibitor, Skin depigmenting agent

(C) 2020 The Authors. Published by Innovare Academic Sciences Pvt Ltd. This is an open access article under the CC BY license (http://creativecommons.org/licenses/by/4.0/) DOI: http://dx.doi.org/10.22159/ijap.2020v12i3.36957. Journal homepage: https://innovareacademics.in/journals/index.php/ijap

\section{INTRODUCTION}

Melanin is a biopolymer synthesized by the melanocyte cells in the cell organelles called melanosomes in epidermal layers of the skin [1-3]. Mature melanosomes are then transferred via intermediary dendrites into ceratine, resulting in the dark-colored coating on the corneum layer of skin epidermis [4-7]. Naturally, melanin serves as a photoprotective agent that protects DNA from damage due to UV radiation [8-10].

Melanin synthesized process is a combination of enzymatic catalysis and chemical reactions with tyrosinase [11-14] as the major enzyme. Moreover, tyrosinase can cause enzymatic browning in raw fruits, vegetables, and beverages.

This enzyme plays a critical role in changing substrates in the form of L-tyrosine into L-dihydroxyphenylalanine (L-DOPA) via hydroxylation reaction, and the change of L-DOPA becomes dopaquinone through oxidation $[15,16]$. This quinone compound is highly reactive and can polymerize spontaneously that at the end of the reaction it forms the melanin compounds. The formation of melanin is responsible for skin pigmentation condition that would interfere with the aesthetics of human [17-19]. Moreover, hyperpigmentation is caused by the accumulation of excess melanin production. It can cause quite serious skin problems, such as melasma, post-inflammatory melanoderma, solar lentigo, ochronosis exogenous, and dermatosis papu-losanigra [20-23]. Inhibition of the enzymatic activity of tyrosinase, both competitive and noncompetitive, is widely used as a key strategy in the development of depigmentation agent, either as cosmetics or the treatment of hyperpigmentation problems [24-27].

Some of the most used tyrosinase enzyme inhibitor agents are hydroquinone [11, 28, 29], kojic acid [30-33], and arbutin [34-38]. Hydroquinone is a tyrosinase inhibitor agent that has been used for a long time and become the gold standard in the treatment of hyperpigmentation in the USA [39, 40]. However, the use of hydroquinone in cosmetic preparations has been banned by FDA, and only allowed for the use of physician prescription. The FDA requested the use of hydroquinone is not exceeded more than 1.5$2.0 \%$ in skin cosmetics product. This is due to the effect that hydroquinone can cause ochronosis exogenous and cytotoxic in the presence of reactive metabolites, such as, hydroxyl benzoquinone and p-benzoquinone [41-45].

Natural product that contains stilbenes, uses tyrosinase inhibitors as skin whitening agents [46]. Sapindus mukorossi that grows in tropical and sub-tropical regions of Asia has weak bioactivity against tyronase with $\mathrm{IC}_{50}$ values of $17.8 \%$ and $12.3 \%$ at $10 \mu \mathrm{g} / \mathrm{ml}$ [47]. Curcumin-Mn and $\mathrm{Zn}$ has a potent as anti-tyrosinase capacity as a depigmentation agent [48] that can be studied further.

In the previous study, Celastrus paniculatus seed oil exhibited superior tyrosinase inhibition activity than the standard ascorbic acid, kojic acid and arbutin [49]. Senol et al. found natural antityronase from the aerial parts of 33 Turkish Scutellaria species. However, the plant's activity is moderate, ranged from $39.57 \%$ to $51.58 \%$ inhibition [50]. The plants from common tropical plant species in the Indian subcontinent and Southeast Asia have been observed as a skin whitening treatment, and it has sub-nano molar activity. However, the $\mathrm{IC}_{50}$ is 60 times higher than kojic acid [51]. Tyrosinase inhibitory activity also is shown by the enzymatic hydrolysates of the collagen that obtained from the skin of squid (Todarodespacificus) [52].

Hydroquinone has very effective to inhibit melanogenesis thus can be used as a depigmentation agent. However, metabolite results from oxidation of hydroquinone by tryrosinase cause seriously adverse effects. DNA is damaged by hydroquinone as showed in studies against rodent models [53]. Furthermore, hydroquinone is banned in European Union, US FDA, and also in Indonesia for the cosmetic active ingredient.

Some derivatives of hydroquinone has become much better than hydroquinone due to the decreasing its cytotoxycity, such us arbutin derivatives [54].

Kojic acid is an effective tyrosinase inhibitor agent both in vitro and in vivo [55-58]. However, these compounds have been banned in Japan for causing allergies and mutagenic [59]. Arbutin has been traditionally used by Japanese people to treat skin pigmentation disorders [60]. It is known to be an effective agent to address skin hyperpigmentation disorders. Its cytotoxic properties against melanocyte cells are lower than 
hydroquinone, but depigmentation activity of arbutin is still far below hydroquinone depigmenting activity $[61,62]$.

In 2005, Boissy and his team synthesized a tyrosinase inhibitor agent and used arbutin as the parent compound, dA (4-[Tetrahydro2H-Pyrans-2-yl) oxy] phenol), by removing the hydroxy group on the compound of arbutin. This compound is proved to be more effective than other tyrosinase agent inhibitors and more secure [63, 64]. There are known two form of arbutin, $\alpha$-and $\beta$-arbutin. The both form of arbutin is hydroxylated by oxytyrosinase in ortho position of the catechol group thus to give rise to a complex formed by mettyrosinase with ydroxylated [37]. $\beta$-arbutin is naturally compound from Ericaceae and Saxi fragaceae [65]. On the other hand, $\alpha$-arbutin is synthesized from hydorquinane using enzymatic or chemical reaction $[66,67]$. In many study, $\alpha$ and $\beta$-arbutin has inhibit the formation melanin in B16 cell induced by $\alpha$-melanocyte stimulating hormone $(\alpha-\mathrm{MSH})$ and inhibit tyronasinase activity [68]. Sugimoto et al. [62] explained that the $\alpha$-arbutin has an effective and safe to use as skin lightening that decrease the cellular tyrosinase activity of HMV-II (Human Melanoma cell). The molecular mechanism of $\alpha$ arbutin against tyrosinase activity is studied by Gilibro et al. [69]. However, arbutin has some side effect to human skin in some cases. Arbutin cause allergic [70-72]. There are cases of allergic contact dermatitis caused by arbutin from Japan patients [71, 73]

The other derivative of hydroquinone is deoxyarbutin (dA) that has more effective and safe clinically than arbutin to therapy hyperpigmentation. $\mathrm{dA}$ is second generation derivatives of hydroquinone [74]. $\mathrm{dA}$ is less cytotoxic than the others hydroquinone derivatives. This review summarized melanogenesis process and the role of tyrosinase inhibitor through the latest effective and safety compound, dA [75].

The arrangement is automatically carried out by a substrate-induced melanogenic pathway (L-tyrosine and/or L-DOP). This arrangement will also regulate the function of melanocytes by structural or regulatory protein activity and through mediating melanogenesis and melanin itself [76].

\section{Melanogenesis}

Melanin is produced in the melanocytes cells through the process of melanogenesisin enzymatic or chemical reactions. Melanogenesis occurs in specialized organelles within melanocytes cells called melanosomes [77-80]. In normal circumstances, melanin serves to protect the skin from the damaging effects of UV radiation. The accumulation of abnormal melanin will cause aesthetic effects and disrupt health [75]. One of the clinical manifestations of abnormally accumulated melanin is the incidence of melasma, i.e. hyperpigmentation on the epidermis or dermis in the facial area that affects mainly the individual light-skinned, which included skin types III-IV, according to the classification of Fitzpatrick. It is more prevalent in women than associated with hormonal factors [81]. The auto regulate automatically itself is carried out by a substrateinduced melanogenic pathway (L-tyrosine and/or L-DOP) and this arrangement will also regulate the function of melanocytes by structural or regulatory protein activity and through mediating melanogenesis and melanin itself [15].

The main targets are developed for depigmentation that inhibits the activity of tyrosinase enzyme, which is a precursor for the melanin synthesis [82]. Tyrosinase is a glycoprotein located on the membrane of melanosomes, and also dominated inside melanosomes, trans membrane, and in the cytoplasm of melanocyte cells. It is a monooxidase copper-dependent enzyme that has a role in catalyzing the conversion of monofenolic compound (L-tyrosine) into difenolic compound (L-DOPA) through hidroxilation process, and convert difenolic compound to quinone (benzoquinone) compound through an oxidation process [83]. The role of tyrosinase enzyme in melanin formation mechanism in the melanosomes within melanocytes cells and the processes that occur during melanogenesis itself [84]

The main substrate on melanogenesis enzymatic reaction is tyrosine. Tyrosine is hydroxylated by tyrosinase enzyme to be dopaquinone as a product of them. Dopaquinone will react with the cysteine-S to produce 5-cysteinyldopa and 2-S-cysteinyldopa in limited quantities.
Cysteinyldopa is oxidized to produce benzothiazine followed by pheomelanin, a red pigment that causes blond hair. The absence of cysteine causes additional intramolecular amino groups for dopaquinone changed to be cyclodopa (Leucodopa-chrome). This compound then undergoes auto-oxidation and turned into dopa and dopachrome. Dopa is a substrate of tyrosinase enzyme too, therefore will oxidize back into dopaquinone. Next, dopachrome decomposes gradually and forms DHI and DHICA in very small amounts. The process is catalyzed by the tyrosinase-related enzyme protein-2 (Tyrp2), which is now known as dopachrome tautomerase (Dct). Finally, hydroxyl indole compound is oxidized to eumelanin. Tyrosinase-related protein-1 (tyrp1) catalyzes the conversion of partially enzyme DHICA into eumelanin. Eumelanin is a blackish brown pigment that produces skin hyperpigmentation [85].

After the formation of melanin, melanin-shrouded melanosomes will be taken by melanocytes and transferred to the keratocytes cells, namely keratinocytes that have undergone differentiation. The transfer from melanocytes to keratinocytes is made through the tentacles of melanocyte (dendrites) approaching keratinocytes in the stratum above the basal layer. In the basal stratum 1, melanocyte cells are surrounded by 30-40 keratinocytes cells [86, 87].

\section{Melanogenesis at a subcellular level}

In subcellular level, melanogenesisis encoded by the melanogenesisrelated enzyme, including tyrosine, Tryp 1 and Tyrp 2 that are regulated through intracellular pathways. The signal of this pathway is initiated by some kinds of hormones including interleukin, growth factor, and prostaglandin. Some hormones also respond to a complex signal for their exposure to UV radiation or other stimulation that comes from the environment outside the body. Fig. 2 shows several signaling pathways that have been known to be actively involved in the process of melanogenesis at the subcellular level. All three of the signaling pathway involving microphthalmia-associated transcription factor (MITF), which is a transcription factor with the domain structure of basic helix-loophelix leucine zipper. In addition, its role in the proliferation and differentiation of melanocyte cell survival, MITF is also an important regulator that regulates the expression of genes for the formation of tyrosinase, Tyrp1, and Tyrp2. Up-regulation of MITF activity will activate the expression of the melanogenesis-related enzyme, which in turn will stimulate melanogenesis and vice versa, while down-regulation of MITF activity will suppress the expression of this enzyme that would inhibit melanogenesis [24, 88].

Alpha-melanocyte stimulating hormone $(\alpha-\mathrm{MSH})$ is a peptide derived from proopio melano cortine (POMC) [89], which regulates melanogenesis through cAMP pathway. $\alpha$-MSH is released into the systemic circulation of the pituitary. It is related to melanocortin peptides, derived from the precursor POMC, which also expressed in numerous CNS and peripheral structures.

When bound to its receptor namely melanocortine 1 receptor (MC1R) on melanocytes cell membrane, these hormones activate adenylyl cyclase (AC) to produce intracellular cAMP as the second messenger through the activation of G-protein-coupled receptors (GPCR). cAMP activates protein kinase A (PKA), which subsequently activate the MITF gene expression through phosphorilasic AMP response element-binding protein (CREB). Afterwards, MITF efficiently activates the melanogenesis-related enzyme and stimulates melanogenesis. Once $\alpha$ MSH is bound to the MC1R, the incidence of melanogenesis will increase by more than 100 times. Likewise with other POMC peptides are $\beta$-MSH and adrenocorticotropic hormone (ACTH), will stimulate melanogenesis via the same pathways [90].

Other signaling pathways that also activate MITF gene expression are the Wnt signaling pathway. The main key to this pathway is namely intracellular level of $\beta$-catenin. When the Wnt signal is absent, $\beta$-catenin is phosphorylated by glycogen synthase kinase- $3 \beta$ (GSK-3 $\beta$ ). This phosphorylation recognized by the ubiquitin ligase complex, will degrade $\beta$-catenin [91]. Conversely, the signal Wntactivated would regulate GSK-3 $\beta$, causing the accumulation of $\beta$ catenin cytoplasmic translocates to the nucleus and forms a complex with the T-cell factor (TCF) and lymphocyte enhancer factor-1 (LEF), to download the up-regulation of gene expression MITF which in turn activates melanogenesis reaction via the same pathways [92]. 
In the opposite of the aforementioned path the path of an extracellular signal-regulated kinase (ERK) regulates melanogenesis through MITF protein degradation. ERK activates the phosphorylation of MITF through serine 73, followed by MITF ubiquination and proteasome-mediated degradation. As the result, the ERK pathway activation will inhibit melanogenesis, associated with down-regulation of MITF activity [34,93].

\section{The internal and external factors of melanogenesis}

Melanocytes produce POMC peptides, cytokines, NO, prostaglandins, and leukotrienes that are activated through autocrine or paracrine pathway, associated with the production of adenylcyclase and cAMP as shown fig. 1 . Those receptors are within the immune response and inflammatory response, which are also involved in the process of pigmentation of the skin [20]. This creates some incidences of melanoderma postinflammatory, hyperpigmentation after an injury to the skin, and hyperpigmentation post-infection as in the case of chikungunya; as for other receptors in the melanocyte cells that are tied to the production of adenylcyclase and cAMP as muscarinic receptor and estrogen receptor $\alpha$ and $\beta$. Therefore, increased production of estrogen during pregnancy can cause hyperpigmentation such as melasma, hyperpigmentation areolar, and line nigricans [20].

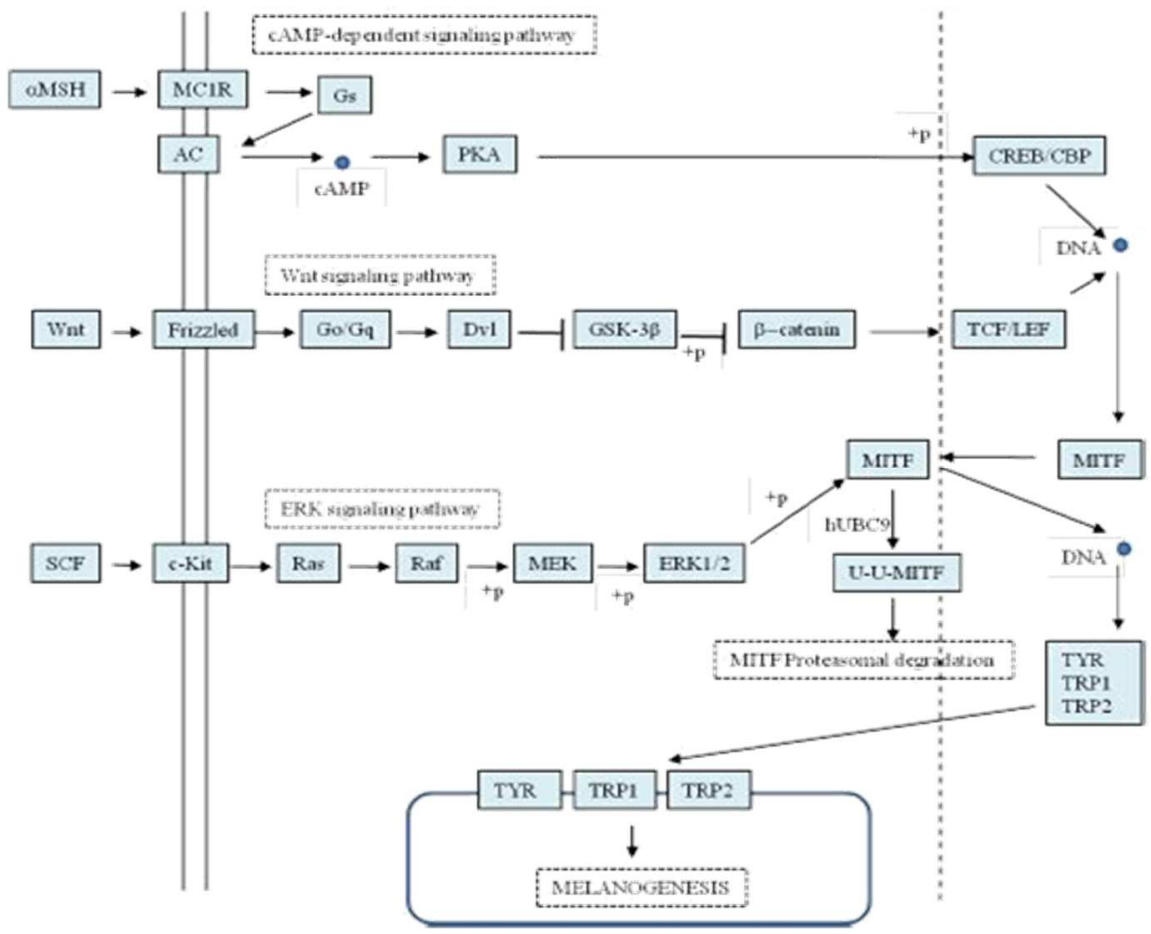

Fig. 1: Melanogenesis at the subcellular level [34]

Many extrinsic factors can trigger the occurrence of hyperpigmentation, such as the use of several kinds of drugs, chemicals, and even substances that are commonly used for the treatment of anti-aging and melisma, for example, hydroquinone which causes oncronosis exogenous-the formation of the blue to black pigment on skin tissue [34]. UV radiation is the main cause of skin hyperpigmentation. Rapid pigmentation can occur 5-10 min after exposure to UVR and disappear after a few minutes or days later. It usually occurs because of UVA radiation or delayed pigmentation in 3-4 d after exposure to UVR, and disappear after a few weeks due to UVA and UVB radiation [20].

UV radiation induces DNA damage which will be activated by p53 (tumor protein suppressor). P53 stimulates the POMC gene undergone the post-translational, such asACTH, $\alpha$-MSH, and $\beta$ endorphin. The POMC peptide binds to MC1R on melanocytes, which further regulates melanogenesis through cAMP pathway [94]. Melanin is produced and transferred back to the keratinocytes. It has been mentioned that one POMC peptides bound to the MC1R, it lead a hundred times of melanogenesis incidence [34] that cause hyperpigmentation due to exposure of UV radiation.

\section{Deoxyarbutin synthesis}

dA compound (4-[Tetrahydro-2H-Pyrans-2-yl) oxy] phenol) designed by Boissy and his team for the first time in 2005, used quantitative structure-activity relationships (QSAR). This method is used as an approach to understanding the structural characteristics of the compounds. Although many techniques can be used in QSAR methods, but a basic understanding of this method is to convert the structure of a molecule or a part of the molecular structure to become a value numerically. In consequence, the value will be correlated with traits desired in an unknown compound [64].

The properties are optimized in this design. It is the competitive inhibition (at the binding site) of mushroom tyrosinase enzyme, inhibitor resistance to oxidation by the enzyme tyrosinase (thus can be an alternative substrate) and the molecule's ability to penetrate the skin. $\mathrm{dA}$ compounds are synthesized by eliminating the hydroxyl groups of the side chains of glucose group from arbutin as the parent compound as shown in fig. 2 [64]. The facile and highly efficient preparation of deoxyarbutin is recommended using a one-step catalyst-free continuous-flow etherification protocol. The one-step direct etherification obtains $\mathrm{dA}$ from hydroquinone through a continuous-flow, catalyst-free process [95].<smiles>Oc1ccc(OC2C(O)C(O)C(O)C(O)C2O)cc1</smiles>

Arbutin<smiles>Oc1ccc(OC2CCCCO2)cc1</smiles>

Deoxyarbutin
Fig. 2: Conversion of arbutin compound into dA 


\section{The activity, efficacy and safety of deoxyarbutin}

$\mathrm{dA}$ is safer and less cytotoxic compared with hydroquinone [96]. Based on in vitro experiments against mushroom tyrosinase, it turns out that dA effectively inhibits mushroom tyrosinase with Ki 10 times lower than hydroquinone and 350 times lower than arbutin. The inhibition coefficient of $\mathrm{dA}$, hydroquinone, kojic acid, and arbutinin $\mu \mathrm{M}$ is 0.05 , $0.54,7.70,17.60$, respectively. In another study, $d A$ is still stronger than hydroquinone that becomes the gold standard for melisma treatment. $\mathrm{IC}_{50}$ of $\mathrm{dA}(17.5+0.5 \mu \mathrm{mol} / \mathrm{l})$ is lower than hydroquinone $(73.7+9.1 \mu \mathrm{mol} / \mathrm{l})$ when using mushroom tyrosinase assay and an inhibition coefficient of $\mathrm{dA}$ and hydroquinone at Ki 21.6+1.0 $\mu \mathrm{mol} / \mathrm{l}$ and 83.1+5.9, respectively [97]. dA also could fight against tumour in vitro and in vivo. $\mathrm{dA}$ inhibits the proliferation and metastasis of tumour via a p38-mediated mitochondria [98].

Furthermore, dA in hairless guinea pigs shows skin lightening activity immediately and extended, where this activity is reversible after $8 \mathrm{w}$ of discontinuation of topical application of dA. In contrast to the same study, hydroquinone skin-lightening activity has shorter onset but not extended, whereas kojic acid and arbutin show in significant skin lightening effect during the test [97]. Hydroquinone has some side effects with long-term application, such as melanocyte destruction, ochronosis and contact dermatitis [35].

In clinical trials conducted human subjects, topical application of $\mathrm{dA}$ in $12 \mathrm{w}$ resulted in significant skin lightening on the subject who has light skin and improvements in solar lenities experienced in the dark-skinned population [64].

Other clinical trials conducted on the subject of 25 men and women ranged from 18-60 y old, for $5 \mathrm{w}$ experiment, with the type of postexposure test (subjects were given prior to UV exposure for $7 \mathrm{~d}$ (tanning process) with a dosage test). The result showed that the percentages of the final tanning in control subjects (who were not given dosage), the subjects who had hydroquinone therapy and the subjects with $\mathrm{dA}$ treated are $44.6 \%, 51.6 \%$ and $37.3 \%$ respectively [63].

$\mathrm{dA}$ is a reversible inhibitor of the tyrosinase enzyme. It shows that the $\mathrm{dA}$ does not permanently damage the melanocytes. In further research by Hamed and his team in 2006, the study observed human melanocyte cell cultures. It showed that the maximum concentration of cell viability of $d A$ is $95 \%$ higher than hydroquinone. It indicates that $\mathrm{dA}$ is not cytotoxic/cytostatic rather than $\mathrm{HQ}[63,97]$.

Some of the previous toxicity tests show that $\mathrm{dA}$ is relatively safer than hydroquinone. Oral LD50 in rats as the subject to $\mathrm{dA}$ and hydroquinone is $>2000 \mathrm{mg} / \mathrm{kg}$ and $298 \mathrm{mg} / \mathrm{kg}$, respectively. The skin sensitization test proved that it has no potential to sensitize skin on $\mathrm{dA}$ treatment, while hydroquinone treatment shows potential to sensitize the skin. Dermal toxicity tests conducted with rats show that the dermal LD50 dA is more than $2000 \mathrm{mg} / \mathrm{kg}$ of body weight, while NOAEL values for hydroquinone is $74 \mathrm{mg} / \mathrm{kg} /$ day [99]. NaiFang Chang et al. found that UVB-irradiated Arbutin and dA have strong cytotoxicity for the fibroblast cells [100]. Arbutin and dA is irradiated by UVB to form hydroquinone and end of product the toxic compound of 4-benzophenone [101]. dA has LD50 $367 \mathrm{mg} / \mathrm{kg}$ in males and $314 \mathrm{mg} / \mathrm{kg}$ in females rats by serving for $4 \mathrm{~d}$.

\section{The stability of deoxyarbutin}

In terms of stability, it is known that $\mathrm{dA}$ is thermolabile, especially in an aqueous solvent solution. When $\mathrm{dA}$ is stored for $14 \mathrm{~d}$ at a temperature of $45^{\circ} \mathrm{C}, \mathrm{dA}$ levels is plummeted to undetectable. At 25 ${ }^{\circ} \mathrm{C}$, dA level is decreased from $96.14 \%$ in the first day to $49.42 \%$ on 21th day. At $4{ }^{\circ} \mathrm{C}, \mathrm{dA}$ relatively shows a stable condition with concentration at $93.43 \%$ up to $21 \mathrm{~d}$ [102]. In the same study, $\mathrm{dA}$ degradation occurs in an aqueous solvent at high temperatures. Decreased dA levels per unit of time at high temperatures are directly proportional to an increase in hydroquinone levels [103].

In a solution with a solvent containing water within storage conditions at an elevated temperature, free electrons in the solvent can interact with oxygen atoms that lie between phenol group and tetrahydro-2H-pyrans on dA. Thus, it is degraded to hydroquinone and other molecules, such as tetrahydro-2H-pyrans-2-ol. The resulting hydroquinone (colorless) in aqueous solution will be oxidized to benzoquinone which changes the color of the solution to be brownish (fig. 3).

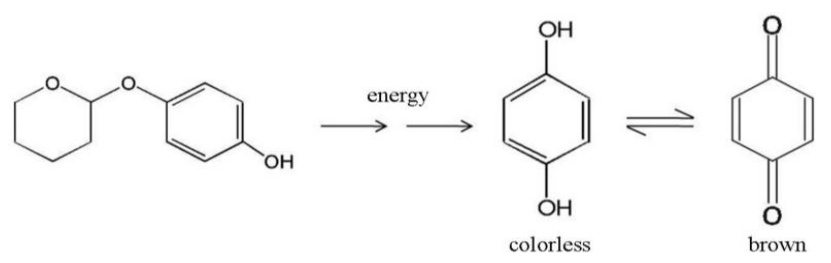

Fig. 3: The dA degradation mechanisms in an aqueous solution becomes hydroquinone (colorless) and benzoquinone (brown)

In an attempt to increase the stability of $\mathrm{dA}$ in preparations, some studies have observed $\mathrm{dA}$ stability in the system anhydrous emulsion formula with a base polyol-in silicone. The quantity of $\mathrm{dA}$ and the accumulation of hydroquinone as $\mathrm{dA}$ degradation products in aqueous solution are measured using HPLC [104]. The developed HPLC analytical method meets the validation criteria made by ICH. Muchtaridi et al. perform the analysis of dA using column C-18, UV detector $225 \mathrm{~nm}$, methanol: water $(60: 40 \mathrm{v} / \mathrm{v})$ as the mobile phase with isocratic elution; the flow rate is at $1 \mathrm{ml} / \mathrm{min}$ and the running time is $8 \mathrm{~min}$.

The research demonstrates that the anhydrous emulsion systems with a polyol-in silicone as a base (oil based), improve the stability $\mathrm{dA}$ in preparations and lead to delays degradation of deoxyarbutinin becoming hydroquinone at temperatures of $25^{\circ} \mathrm{C}$ and 45 ${ }^{\circ} \mathrm{C}[102]$.

As well as being thermolabile, arbutin and $\mathrm{dA}$ in aqueous solution are photolabile and create degradation products, such as hydroquinone. The concentration of hydroquinone increases during UV radiation in an aqueous solution containing arbutin and $\mathrm{dA}$ [101]. The release of the $o$-diphenol product forming deoxyarbutin is predicted be slower than in the case of $\beta$-arbutin using molecular modeling methods [105]. It contributes to its oxidation to a quinone before released from the protein into the water phase.

In an effort to increase the stability of arbutin and dA against UVR exposure, Yang and his team (2013) in their study, added Benzophenone-4 in $\mathrm{dA}$ aqueous solutions and arbutin aqueous solutions. The treatment proved that it can increase the stability of the two substances against UV radiation exposure although not significant [101]. dA is insoluble in water, but it easily degrades in aqueous conditions. Tofani et al. (2016) formulates nanostructured lipid carriers (NLCs) to increased topical delivery of dA to inhibit tyrosinase during melanogenesis [106].

\section{CONCLUSION}

The prospective of $\mathrm{dA}$ agent as a depigmentation agenthas a good efficacy, safety and stability. dA is tyrosinase inhibitor with good efficacy and relatively safe. It has higher potential as depigmentation agent than hydroquinone, which has been the gold standard of treatment of hyperpigmentation in the last decade. It has been demonstrated both in vitro and in vivo that the inhibition constants of $\mathrm{dA}$ and that $\mathrm{IC}_{50}$ are lower than hydroquinone. In terms of security, $\mathrm{dA}$ is safer than hydroquinone, which has low potential to be 
cytotoxic. In addition, based on other toxicity tests, dA is known to be more secure. However, $\mathrm{dA}$ is the rmolabile and photo labile. Several attempts have been made to improve the stability, such as making anhydrous emulsion formulations and adding sunscreen agents into the formula preparations. The development strategy and more advanced formulations of $\mathrm{dA}$ is required to improve the stability Therefore, not only preparations with $\mathrm{dA}$ have good potential and security but also good quality and stability during in storage, due to the effectiveness and safety of an active compound that cannot be achieved in unstable or degraded preparation in storage condition.

\section{CONTRIBUTION}

Muchtaridi Muchtaridi give the main idea of this article and also write the substances of this paper. Mentari Luthfika Dewi drafted of the paper and completed of references.

\section{ABBREVIATION}

dA: deoxyarbutin, Ki: Inhibition constant, UV: Ultra violet

\section{FUNDING}

Nil

\section{AUTHORS CONTRIBUTIONS}

All the authors have contributed equally.

\section{CONFLICT OF INTERESTS}

Conflict of interest declared none.

\section{REFERENCES}

1. Ali SA, Naaz I. Biochemical aspects of mammalian melanocytes and the emerging role of melanocyte stem cells in dermatological therapies. Int J Health Sci 2018;12:69-76.

2. Mahanty S, Kawali AA, Dakappa SS, Mahendradas P, Kurian M, Kharbanda V, et al. Aqueous humor tyrosinase activity is indicative of iris melanocyte toxicity. Exp Eye Res 2017;162:79-85.

3. Zhang Y, Helke KL, Coelho SG, Valencia JC, Hearing VI, Sun S, et al. Essential role of the molecular chaperone gp96 in regulating melanogenesis. Pigment Cell Melanoma Res 2014;27:82-9.

4. Ando H, Niki Y, Ito M, Akiyama K, Matsui MS, Yarosh DB, et al. Melanosomes are transferred from melanocytes to keratinocytes through the processes of packaging, release, uptake, and dispersion. J Invest Dermatol 2012;132:1222-9.

5. Cichorek M, Wachulska M, Stasiewicz A, Tymińska A. Skin melanocytes: biology and development. Postepy Dermatologii I Alergologii 2013;30:30-41.

6. Serre C, Busuttil V, Botto JM. Intrinsic and extrinsic regulation of human skin melanogenesis and pigmentation. Int J Cosmet Sci 2018;40:328-47.

7. Scott G. Demonstration of melanosome transfer by a shedding microvesicle mechanism. J Invest Dermatol 2012;132:1073-4.

8. Coelho SG, Yin L, Smuda C, Mahns A, Kolbe L, Hearing VJ. Photobiological implications of melanin photoprotection after UVB-induced tanning of human skin but not UVA-induced tanning. Pigment Cell Melanoma Res 2015;28:210-6.

9. D'Orazio J, Jarrett S, Amaro Ortiz A, Scott T. UV radiation and the skin. Int J Mol Sci 2013;14:12222-48.

10. Abdassah M, Aryani R, Surachman E, Muchtaridi M. In vitro assessment of effectiveness and photostability avobenzone in cream formulations by combination ethyl ascorbic acid and alpha tocopherol acetate. J Appl Pharm Sci 2015;5:70-4.

11. Pillaiyar T, Manickam M, Namasivayam V. Skin whitening agents: medicinal chemistry perspective of tyrosinase inhibitors. J Enzyme Inhib Med Chem 2017;32:403-25.

12. Zaidi KU, Ali AS, Ali SA, Naaz I. Microbial tyrosinases: promising enzymes for pharmaceutical, food bioprocessing, and environmental industry. Biochem Res Int 2014. p. 16. https://doi.org/10.1155/2014/854687

13. Bang E, Noh SG, Ha S, Jung HJ, Kim DH, Lee AK, et al. Evaluation of the novel synthetic tyrosinase inhibitor (Z)-3-(3-bromo-4hydroxybenzylidene) thiochroman-4-one (MHY1498) in vitro and in silico. Molecules (Basel, Switzerland) 2018;23:3307.
14. Singh BK, Park SH, Lee HB, Goo YA, Kim HS, Cho SH, et al. Kojic acid peptide: a new compound with anti-tyrosinase potential. Annals Dermatol 2016;28:555-61.

15. Slominski A, Zmijewski MA, Pawelek J. L-tyrosine and Ldihydroxyphenylalanine as hormone-like regulators of melanocyte functions. Pigment Cell Melanoma Res 2012;25:14-27.

16. Pająk M, Pałka K, Winnicka E, Kańska M. The chemo-enzymatic synthesis of labeled l-amino acids and some of their derivatives. J Radioanal Nucl Chem 2018;317:643-66.

17. Araji S, Grammer TA, Gertzen R, Anderson SD, Mikulic Petkovsek M, Veberic R, et al. Novel roles for the polyphenol oxidase enzyme in secondary metabolism and the regulation of cell death in walnut. Plant Physiol 2014;164:1191-203.

18. Sugumaran M. Reactivities of quinone methides versus oquinones in catecholamine metabolism and eumelanin biosynthesis. Int J Mol Sci 2016;17:1576.

19. Klopcic I, Sollner Dolenc M. Chemicals and drugs forming reactive quinone and quinone imine metabolites. Chem Res Toxicol 2018;32. Doi: 10.1021/acs.chemrestox.8b00213

20. Videira IFdS, Moura DFL, Magina S. Mechanisms regulating melanogenesis. An Bras Dermatol 2013;88:76-83.

21. Vandecasteele SJ, De Ceulaer J, Wittouck E. Tigecycline induced hyperpigmentation of the skin. Open Forum Infect Dis 2016;3:33-9.

22. Yamaguchi Y, Hearing VJ. Physiological factors that regulate skin pigmentation. BioFactors (Oxford, England) 2009;35:193-9.

23. Vandecasteele SJ, De Ceulaer J, Wittouck E. Tigecycline induced hyperpigmentation of the skin. Open Forum Infect Dis 2016;3:ofw033-ofw033.

24. D'Mello SAN, Finlay GJ, Baguley BC, Askarian-Amiri ME. Signaling pathways in melanogenesis. Int $\mathrm{J}$ Mol Sci 2016;17:1144.

25. Wang Y, Hao MM, Sun Y, Wang LF, Wang H, Zhang YJ, et al. Synergistic promotion on tyrosinase inhibition by antioxidants. Molecules (Basel, Switzerland) 2018;23:106.

26. Alam MB, Bajpai VK, Lee J, Zhao P, Byeon JH, Ra JS, et al. Inhibition of melanogenesis by jineol from scolopendra subspinipes mutilans via MAP-Kinase mediated MITF downregulation and the proteasomal degradation of tyrosinase. Sci Reports 2017;7:45858.

27. Cho BR, Jun HJ, Thach TT, Wu C, Lee SJ. Betaine reduces cellular melanin content via suppression of microphthalmia-associated transcription factor in B16-F1 murine melanocytes. Food Sci Biotechnol 2017;26:1391-7.

28. Chen WC, Tseng TS, Hsiao NW, Lin YL, Wen ZH, Tsai CC, et al. Discovery of highly potent tyrosinase inhibitor, T1, with significant anti-melanogenesis ability by zebrafish in vivo assay and computational molecular modeling. Sci Rep 2015;5:7995.

29. Rizwana K, Naveed A. Evaluation of depegmenting and antierythemic effects of cosmetic emulgels containing raspberry fruit extract on human cheek skin. Int J Pharm Pharm Sci 2016;9:236-8.

30. Lee YS, Park JH, Kim MH, Seo SH, Kim HJ. Synthesis of tyrosinase inhibitory kojic acid derivative. Arch Pharm (Weinheim) 2006;339:111-4.

31. Saeedi M, Eslamifar M, Khezri K. Kojic acid applications in cosmetic and pharmaceutical preparations. Biomed Pharmacother 2019;110:582-93.

32. Lajis AFB, Hamid M, Ariff AB. Depigmenting effect of Kojic acid esters in hyperpigmented B16F1 melanoma cells. J Biomed Biotechnol 2012. Doi:10.1155/2012/952452

33. Burnett CL, Bergfeld WF, Belsito DV, Hill RA, Klaassen CD, Liebler DC, et al. Final report of the safety assessment of kojic acid as used in cosmetics. Int J Toxicol 2010;29:244S-273S.

34. Chang TS. Natural melanogenesis inhibitors are acting through the down-regulation of tyrosinase activity. Materials 2012;5:1661-85.

35. Chawla S, deLong MA, Visscher MO, Wickett RR, Manga P, Boissy RE. Mechanism of tyrosinase inhibition by deoxy arbutin and its second-generation derivatives. $\mathrm{Br} J$ Dermatol 2008;159:1267-74

36. Tada M, Kohno M, Niwano Y. Alleviation effect of arbutin on oxidative stress generated through tyrosinase reaction with Ltyrosine and L-DOPA. BMC Biochem 2014;15:23-3. 
37. Garcia Jimenez A, Teruel Puche JA, Berna J, Rodriguez Lopez JN, Tudela J, Garcia Canovas F. Action of tyrosinase on alpha and beta-arbutin: a kinetic study. PloS One 2017;12:e0177330e0177330.

38. Lee SY, Baek N, Nam TG. Natural, semisynthetic and synthetic tyrosinase inhibitors. J Enzyme Inhibition Med Chem 2016;31:1-13.

39. Ni-Komatsu L, Tong C, Chen G, Brindzei N, Orlow SJ. Identification of quinolines that inhibit melanogenesis by altering tyrosinase family trafficking. Mol Pharmacol 2008;74:1576-86.

40. Palumbo A, d'Ischia M, Misuraca G, Prota G. Mechanism of inhibition of melanogenesis by hydroquinone. Biochim Biophys Acta 1991;1073:85-90.

41. Al-Saleh I, Elkhatib R, Al-Rouqi R, Al-Enazi S, Shinwari N. The dangers of skin-lightening creams. Toxicol Environ Chem 2012;94:195-219.

42. Westerhof W, Kooyers TJ. Hydroquinone and its analogues in dermatology-a potential health risk. J Cosmet Dermatol 2005;4:55-9.

43. Hutt AM, Kalf GF. Inhibition of human DNA topoisomerase II by hydroquinone and p-benzoquinone, reactive metabolites of benzene. Environ Health Perspect 1996;104 Suppl 6:1265-9.

44. DeCaprio AP. The toxicology of hydroquinone--relevance to occupational and environmental exposure. Crit Rev Toxicol 1999;29:283-330.

45. McGregor D. Hydroquinone: an evaluation of the human risks from its carcinogenic and mutagenic properties. Crit Rev Toxicol 2007;37:887-914.

46. Loizzo MR, Tundis R, Menichini F. Natural and synthetic tyrosinase inhibitors as antibrowning agents: an update. Compr Rev Food Sci Food Saf 2012;11:378-98.

47. Chen CY, Kuo PL, Chen YH, Huang JC, Ho ML, Lin RJ, et al. Tyrosinase inhibition, free radical scavenging, antimicroorganism and anticancer proliferation activities of Sapindus mukorossi extracts. J Taiwan Institute Chem Eng 2010;41:129-35.

48. Nisakorn S, Anongnuch T, Ampa J, Krisada K. Anti-tyrosinase and cytotoxicity activities of curcumin-metal complexes. Int J Pharm Pharm Sci 1970;6:270-3.

49. Ruksiriwanich W, Sringarm K, Jantrawut P. Stability enhancement of celastrus paniculatus seed oil by loading in niosomes. Asian J Pharm Clin Res 2014;7:186-91.

50. Senol FS, Orhan I, Yilmaz G, Cicek M, Sener B. Acetylcholinesterase, butyrylcholinesterase, and tyrosinase inhibition studies and antioxidant activities of 33 scutellaria L. taxa from turkey. Food Chem Toxicol 2010;48:781-8.

51. Wangthong $\mathrm{S}$, Palaga $\mathrm{T}$, Rengpipat $\mathrm{S}$, Wanichwecharungruang SP, Chanchaisak P, Heinrich M. Biological activities and safety of thanaka (Hesperethusa crenulata) stem bark. J Ethnopharmacol 2010;132:466-72.

52. Joy D, Kumar K, Kumar B, Silvipriya K. Collagen from squid and its biological activity. Int J Curr Pharm Res 2017;9:24-6.

53. Nordlund JJ, Grimes PE, Ortonne JP. The safety of hydroquinone. J Eur Acad Dermatol Venereol 2006;20:781-7.

54. Migas P, Krauze Baranowska M. The significance of arbutin and its derivatives in therapy and cosmetics. Phytochem Lett 2015;13:35-40.

55. Noh JM, Kwak SY, Kim DH, Lee YS. Kojic acid-tripeptide amide as a new tyrosinase inhibitor. Biopolymers 2007;88:300-7.

56. Saruno R, Kato F, Ikeno T. Kojic Acid, a tyrosinase inhibitor from aspergillus albus. Agric Biol Chem 1979;43:1337-8.

57. Hashemi SM, Emami S. Kojic acid-derived tyrosinase inhibitors: synthesis and bioactivity. Pharm Biomed Res 2015;1:1-17.

58. Azami F, Tazikeh Lemeski E, Mahmood Janlou MA. Kojic acid effect on the inhibitory potency of tyrosinase. J Chem Health Risks 2017;7. Doi:10.22034/JCHR.2017.544176

59. Nakagawa M, Kawai K, Kawai K. Contact allergy to kojic acid in skin care products. Contact Dermatitis 1995;32:9-13.

60. Ando H, Matsui MS, Ichihashi M. Quasi-drugs developed in Japan for the prevention or treatment of hyperpigmentary disorders. Int J Mol Sci 2010;11:2566-75.

61. Mann T, Gerwat W, Batzer J, Eggers K, Scherner C, Wenck H, et $a l$. Inhibition of human tyrosinase requires molecular motifs distinctively different from mushroom tyrosinase. J Invest Dermatol 2018;138:1601-8.

62. Sugimoto K, Nishimura T, Nomura K, Sugimoto K, Kuriki T. Inhibitory effects of alpha-arbutin on melanin synthesis in cultured human melanoma cells and a three-dimensional human skin model. Biol Pharm Bull 2004;27:510-4.

63. Hamed SH, Sriwiriyanont P, deLong MA, Visscher MO, Wickett RR, Boissy RE. Comparative efficacy and safety of deoxyarbutin, a new tyrosinase-inhibiting agent. J Cosmet Sci 2006;57:291308.

64. Boissy RE, Visscher M, DeLong MA. DeoxyArbutin: a novel reversible tyrosinase inhibitor with effective in vivo skin lightening potency. Exp Dermatol 2005;14:601-8.

65. Chandrashekar B, Chaithra S, Lakshmi NN. Effectiveness and safety of a novel topical depigmenting agent in epidermal pigmentation: an open-label, non-comparative study. Int J Res Dermatol 2018;4:489-94.

66. Liu CQ, Deng L, Zhang P, Zhang SR, Liu L, Xu T, et al. Screening of high alpha-arbutin producing strains and production of alpha-arbutin by fermentation. World J Microbiol Biotechnol 2013;29:1391-8.

67. Seo DH, Jung JH, Lee JE, Jeon EJ, Kim W, Park CS. Biotechnological production of arbutins (alpha-and betaarbutins), skin-lightening agents, and their derivatives. Appl Microbiol Biotechnol 2012;95:1417-25.

68. Lim YJ, Lee EH, Kang TH, Ha SK, Oh MS, Kim SM, et al. Inhibitory effects of arbutin on melanin biosynthesis of alpha-melanocyte stimulating hormone-induced hyperpigmentation in cultured brownish guinea pig skin tissues. Arch Pharm Res 2009;32:367-73.

69. Gillbro JM, Olsson MJ. The melanogenesis and mechanisms of skin-lightening agents--existing and new approaches. Int J Cosmet Sci 2011;33:210-21.

70. Numata T, Tobita R, Tsuboi R, Okubo Y. Contact dermatitis caused by arbutin contained in skin-whitening cosmetics. Contact Dermatitis 2016;75:187-8.

71. Oiso N, Tatebayashi M, Hoshiyama Y, Kawada A, Allergic contact dermatitis caused by arbutin and dipotassium glycyrrhizate in skin-lightening products. Contact Dermatitis 2017;77:51-3.

72. Matsuo $\mathrm{Y}$, Ito A, Masui $\mathrm{Y}$, Ito $\mathrm{M}$. A case of allergic contact dermatitis caused by arbutin. Contact Dermatitis 2015;72:404-5.

73. Matsuo $\mathrm{Y}$, Ito A, Masui $\mathrm{Y}$, Ito M. A case of allergic contact dermatitis caused by arbutin. Contact Dermatitis 2015;72:4045.

74. Martin C, Portet C, Bantz P, Brun JP, Ruperti A, Mallet MN, et al. [Pharmacokinetics and tissue penetration of single-dose netilmicin used for antibiotic prophylaxis during colo-rectal surgery]. Pathol Biol (Paris) 1991;39:507-10.

75. Yang $\mathrm{CH}$, Chang NF, Chen YS, Lee SM, Lin PJ, Lin CC. Comparative study on the photostability of arbutin and deoxy arbutin: sensitivity to ultraviolet radiation and enhanced photostability by the water-soluble sunscreen, benzophenone4. Biosci Biotechnol Biochem 2013;77:1127-30.

76. Sauriasari R, Azizah N, Basah K. Tyrosinase inhibition, 2,2diphenyl-1-picrylhydrazyl radical scavenging activity, and phytochemical screening of fractions and ethanol extract from leaves and stem bark of matoa (Pometia pinnata). Asian J Pharm Clin Res 2017;10:85-9.

77. Hirobe T. Keratinocytes regulate the function of melanocytes. Dermatol Sinica 2014;32:200-4.

78. Nishimura EK. Melanocyte stem cells: a melanocyte reservoir in hair follicles for hair and skin pigmentation. Pigment Cell Melanoma Res 2011;24:401-10.

79. Tachibana M. Sound needs sound melanocytes to be heard. Pigment Cell Res 1999;12:344-54.

80. Steel KP, Barkway C. Another role for melanocytes: their importance for normal stria vascularis development in the mammalian inner ear. Development 1989;107:453-63.

81. Vashi NA, Kundu RV. Facial hyperpigmentation: causes and treatment. Br J Dermatol 2013;169 Suppl 3:41-56.

82. Bae Harboe YSC, Park HY. Tyrosinase: a central regulatory protein for cutaneous pigmentation. J Investigative Dermatol 2012;132:2678-80. 
83. Uchida $\mathrm{R}$, Ishikawa $\mathrm{S}$, Tomoda $\mathrm{H}$. Inhibition of tyrosinase activity and melanine pigmentation by 2-hydroxytyrosol. Acta Pharm Sinica B 2014;4:141-5.

84. Ito S, A chemist's view of melanogenesis. Pigment Cell Res 2003;16:230-6.

85. Kobayashi T, Urabe K, Winder A, Jimenez Cervantes C, Imokawa $\mathrm{G}$, Brewington $\mathrm{T}$, et al. Tyrosinase related protein 1 (TRP1) functions as a DHICA oxidase in melanin biosynthesis. EMBO J 1994;13:5818-25.

86. Chen H, Weng QY, Fisher DE. UV signaling pathways within the skin. J Invest Dermatol 2014;134:2080-5.

87. Li PH, Liu LH, Chang CC, Gao R, Leung CH, Ma DL, et al. Silencing stem cell factor gene in fibroblasts to regulate paracrine factor productions and enhance c-kit expression in melanocytes on melanogenesis. Int J Mol Sci 2018;19:1475.

88. Hsiao JJ, Fisher DE. The roles of microphthalmia-associated transcription factor and pigmentation in melanoma. Arch Biochem Biophys Suppl 2014;563:28-34.

89. Taylor AW. Alpha-melanocyte stimulating hormone (alpha$\mathrm{MSH}$ ) is a post-caspase suppressor of apoptosis in RAW 264.7 macrophages. PLoS One 2013;8:e74488.

90. Rouzaud F, Kadekaro AL, Abdel Malek ZA, Hearing VJ. MC1R and the response of melanocytes to ultraviolet radiation. Mutat Res 2005;571:133-52.

91. Stamos JL, Weis WI. The $\beta$-catenin destruction complex. Cold Spring Harbor Perspect Biol 2013;5:a007898-a007898.

92. Monga SPS. Role and regulation of $\beta$-catenin signaling during physiological liver growth. Gene Expression 2014;16:51-62.

93. Huang HC, Chang SJ, Wu CY, Ke HJ, Chang TM. [6]-Shogaol inhibits $\alpha$-MSH-induced melanogenesis through the acceleration of ERK and PI3K/Akt-mediated MITF degradation. BioMed Res Int 2014. Doi:10.1155/2014/842569.

94. Böhm M, Grässel S. Role of proopiomelanocortin-derived peptides and their receptors in the osteoarticular system: from basic to translational research. Endocrine Rev 2012;33:623-51.

95. Xie X, Xie S, Yao H, Ye X, Yu Z, Su W. Green and catalyst-free synthesis of deoxyarbutin in continuous-flow. Reaction Chem Eng 2019;4:927-31.

96. Shashni B, Sharma K, Singh R, Sakharkar KR, Dhillon SK, Nagasaki Y, et al. Coffee component hydroxyl hydroquinone
(HHQ) as a putative ligand for PPAR gamma and implications in breast cancer. BMC Genomics 2013;14 Suppl 5:S6-S6.

97. Miao F, Shi Y, Fan ZF, Jiang S, Xu SZ, Lei TC. Deoxyarbutin possesses a potent skin-lightening capacity with no discernible cytotoxicity against melanosomes. PloS One 2016;11:e0165338-e0165338.

98. Ma L, Xu Y, Wei Z, Xin G, Xing Z, Niu H, et al. Deoxyarbutin displays antitumour activity against melanoma in vitro and in vivo through a p38-mediated mitochondria associated apoptotic pathway. Sci Rep 2017;7:7197.

99. Dalgard FJ, Gieler U, Tomas Aragones L, Lien L, Poot F, Jemec GBE, et al. The psychological burden of skin diseases: a crosssectional multicenter study among dermatological out-patients in 13 European countries. J Invest Dermatol 2015;135:984-91.

100. Chang NF, Chen YS, Lin YJ, Tai TH, Chen AN, Huang CH, et al. Study of hydroquinone mediated cytotoxicity and hypopigmentation effects from UVB-irradiated arbutin and deoxyarbutin. Int J Mol Sci 2017;18:969.

101. Yang CH, Chang NF, Chen YS, Lee SM, Lin PJ, Lin CC. Comparative study on the photostability of arbutin and deoxy arbutin: sensitivity to ultraviolet radiation and enhanced photostability by the water-soluble sunscreen, benzophenone4. Biosci Biotechnol Biochem 2013;77:1127-30.

102. Lin CC, Yang CH, Chang NF, Wu PS, Chen YS, Lee SM, et al. Study on the stability of deoxyarbutin in an anhydrous emulsion systemy. Int J Mol Sci 2011;12:5946-54.

103. Yang CH, Chen YS, Lai JS, Hong WWL, Lin CC. Determination of the thermodegradation of deoxyArbutin in aqueous solution by high performance liquid chromatography. Int J Mol Sci 2010;11:3977-87.

104. Muchtaridi M, Ida M, Ahmad F. Method development and validation for analysis of deoxyarbutinin anhydrous emulsion system using high-performance liquid chromatography. Int J Appl Pharm 2019;11:172-5.

105. Garcia Jimenez A, Teruel Puche JA, Garcia Ruiz PA, Saura Sanmartin A, Berna J, Garcia Canovas F, et al. Structural and kinetic considerations on the catalysis of deoxyarbutin by tyrosinase. PloS One 2017;12:e0187845-e0187845.

106. Tofani RP, Sumirtapura YC, Darijanto ST. Formulation, characterisation, and in vitro skin diffusion of nanostructured lipid carriers for deoxyarbutin compared to a nanoemulsion and conventional cream. Sci Pharm 2016;84:634-45. 